\title{
A review and participatory extension of game structuring methods
}

\author{
S. W. Cunningham • L. M. Hermans • J. H. Slinger
}

Received: 19 March 2013/Accepted: 31 October 2014/Published online: 21 November 2014

(C) Springer-Verlag Berlin Heidelberg and EURO - The Association of European Operational Research Societies 2014

\begin{abstract}
Problem structuring methods are uniquely suitable for analysing strategically complex problems. There exists a subset of these problem structuring methods which focus specifically on structuring the decision processes by which multiple actors debate and potentially resolve complex problems. These methods include, but are not limited to, analysis of options, conflict analysis, exchange modelling, hypergame analysis and the theory of moves. In this paper, we characterize these methods as "game structuring methods", by describing their common analytical elements and discussing their theoretical pre-commitments. We further develop a standardized approach for using such a game structuring methods within a participatory modelling setting.
\end{abstract}

Keywords Problem structuring methods - Game theory · Participatory methods

\section{Mathematics subject classification 91}

\section{Introduction}

Problem structuring deals with multiple actors, multiple perspectives, conflicts of interest, major uncertainties, and significant unquantifiable factors. The principal goal of problem structuring interventions is to develop a commitment for action (Rosenhead and Mingers 2001). Problem structuring methods have opened up a space of dialogue for more pluralist engagement in more wicked problem

S. W. Cunningham $(\bowtie) \cdot$ L. M. Hermans $\cdot$ J. H. Slinger

Faculty of Technology, Policy Analysis Section, Policy and Management, Delft University of

Technology, Delft, The Netherlands

e-mail: s.cunningham@tudelft.nl 
environments (Rittel and Webber 1973), where there are loose networks of actors, with overlapping interests, who are seeking consensus and developing a drive for action. Problem structuring research involves applied and craftsman-like research where workshops are held, participation is encouraged, and iterative bottom-up calls for action are applied.

There are various methods that aid in problem structuring and the boundaries between problem structuring methods and other methods are relatively poorly defined (Mingers and Rosenhead 2004; Ackermann 2012). The abundance of choice has led to a corresponding concern of how to select, combine and evaluate methods. Furthermore, the continuous development of the field has been accompanied by a natural evolution and shift in the use of terminology. This easily leads to further confusion in a comparative discussion of problem structuring methods.

In an early attempt to provide some more structure to the field, Jackson and Keys (1984) characterized the contexts in which problem structuring methods operate along two dimensions: a system context, and a decision context. According to this classification, complications in problem solving arise either from two aspects of problem contexts: decision makers and systems (Jackson and Keys 1984, p. 474). Problems get more difficult to address if more than one decision maker is involved, if those making the decision are different from those who have to execute it, if external actors may react against decisions taken by others, or if decision makers and their objectives change over time (Jackson and Keys 1984; Ackermann et al. 2005).

In the system context, complexity increases if the system in which the problem is located gets more complex and difficult to understand and when the number of possible course of action available to decision makers as result becomes numerous, with consequences that are in part uncertain (Jackson and Keys 1984, p. 474). Thissen and Walker (2013) follow a similar distinction, where they propose a broad diagnosis of problem situations based on a system analysis as well as an actor or institutional analysis.

This distinction between decision context and system context is a central point of departure for this paper. The system context is about the real-world problem and effective actions to remedy it: what is the problem and what courses of action will help to address it, given the complexity of the system? The decision context is about the process whereby multiple actors will decide about the actions they will actually take: how do we decide what courses of action to take, and how are these actions going to be implemented given the involvement of multiple actors? The system context then is captured by looking at the factors and the relationships between them in a system of interests, enabling the analysis of how new actions could lead to a change in the outcomes of interest. The decision context is captured by looking at the actors and the relationships between them. The context occurs in a decision situation or a policy arena, enabling an analysis of how changes in actor constellations, in rules for collaborative decision making or in actors' perceptions, might lead to a change in the decisions taken. The resultant decisions may be by individual actors or through collaborative joint decision making.

This fundamental difference in context can still be recognized in the contemporary suite of methods and techniques in the field. Techniques with an emphasis on 
analysing the system context of problems include soft systems methodology, cognitive mapping and strategic options development and analysis, strategic choice approach, and robustness analysis. Methods for analysing the decision-makers' context of problems are part of a very different set of techniques, still well within the tradition of problem structuring methods, that consider the character of strategic decision-making processes. Such techniques include the analysis of options, metagames, the graph model for conflict resolution, hypergames, drama theory, and the theory of moves. This distinction between techniques has also been noted earlier, for instance in relation to cognitive mapping and Journey-making: "While cognitive mapping clearly has power to describe the problem, a more powerful technique for strategizing might well be drama theory (Cushman 2006, p. 880)." Many of the problem structuring methods that focus on the decision context are rooted in game theory. Therefore, we will label them as game structuring methods, as a subset of problem structuring methods that focus specifically on the decision environments.

Reviews and assessments of the field of problem structuring by Mingers and Rosenhead (2004) and Ackermann (2012) suggest that the field emphasizes methods which help to provide structure to complex system environments rather more than it emphasizes complex decision environments. Elements of game structuring methods are included in the more encompassing problem structuring approaches such as Journey-making, which includes stakeholder analysis techniques (Eden and Ackermann 1998, 2004). Still, the development in game structuring techniques for problem structuring seems to have stalled in the past few years, when compared to the techniques that put more emphasis on the system contexts. One area of particular importance and difficulty for game structuring methods is their use in a participatory setting.

An awareness of the importance of the decision context often leads to the use of participatory approaches. For instance, DeTombe (2002) describes COMPRAM as a methodology for problem solving that emphasizes the importance of the involvement of multiple actors, to deal with the elements of knowledge, power and emotion in complex societal problems. Most of the problem structuring methods that focus on systems context are commonly used in group settings, within or across organizational boundaries. As such, the process of the intervention is now recognized as a specific element of concern, in addition to the content of the problem (Mingers 2003; Checkland and Winter 2006). Interaction with decision makers and a wider range of actors is also a logical improvement when it comes to game structuring techniques. However, the participatory application of such techniques is hindered by the presence of strategic intentions, hidden agendas, emotional factors and a reluctance or discomfort in discussing matters related to strategic decision processes among participants. These factors complicate the participatory use of techniques focussing on the system context as well, but they will manifest themselves even stronger when focussing on the decision-making context of a problem.

To achieve the goal of performing game structuring exercises in a participatory setting, we need to address the following three challenges. The challenges are first describing how to complement existing problem structuring methodologies to better 
encompass the idea of a game. The second challenge is reinvigorating a segment of the problem structuring literature which in many regards is now quite old. The third challenge is to leaven the existing literature with a richer basis of facilitation and interaction design.

The structure of the paper is as follows. First, we selectively revisit the literature, focussing on a family of related game structuring techniques. Second, we distil a set of critical elements from the literature from which a general purpose methodology for game structuring can be developed. Third, we adapt participatory modelling methods so that we can perform a game structuring exercise live, with real stakeholders. The paper concludes with a general reflection on problem structuring methods, and issues for further research.

\section{A literature review of game structuring methods}

In the following two sections, we claim the need for game structuring techniques as well as problem structuring techniques. We argue that there is an existing tradition of game structuring within the family of problem structuring methodologies. We argue that these techniques draw upon game theory, and therefore share a common language of structural elements. We define the family of game structuring techniques. We argue that the prior theoretical concerns of these techniques are somewhat misplaced, and problematize some new elements. We conclude that there has been a lack of developed methodology for these techniques.

Before we marshal these key arguments for the paper, it is useful to first advance a definition of game structuring techniques. Game structuring methods are a

set of applied methods for finding strategic elements that shape decision processes in a complex problem setting. Such elements include, but are not restricted to, players, actions, payoffs, outcomes and information.

These game structuring methods are widely applicable, and we focus primarily on their use to support live interaction and problem solving with actors in a workshop setting.

\subsection{Origins of the game structuring approach}

This review of the problem structuring literature focusses on five techniques, known as the analysis of options, conflict analysis, exchange modelling, hypergame analysis, and the theory of moves. Two additional refinements-drama theory, and the graph model for conflict resolution-are discussed as part of these techniques. After presenting these techniques, we discuss the fundamental similarities between the various approaches, confirming that there is a distinct game structuring approach within the problem structuring methods' literature.

The first problem structuring method with an explicit game focus was developed by Nigel Howard. His most practical efforts are known as the analysis of options. It was part of the development of metagame analysis (Howard 1971), to which we later turn. For the genesis of this technique in arms control negotiations, see (Ackoff 
1969). The technique itself is known mostly from the grey literature, through later introspection (Howard 1987), and through its references in later techniques and its inclusion as part of metagame analysis in a standard volume on problem structuring methods (Rosenhead and Mingers 1989).

Howard describes the method as "setting up a model by defining actors, options and scenarios" and argues that the method is "strictly independent of game theory" since any number of operations might be performed on the model after it is created (Howard 1987, p. 1). The analysis of options method was developed for behind the scenes strategic support for arms control negotiations. Thus, the method was originally only intended as a means of strategic modelling on behalf of a client. Regardless the technique is highly general, and might also be employed in any number of ways-as an expert opinion method, a group facilitation technique or as a form of war gaming exercise. This versatile technique proved influential and was further adopted and expanded by subsequent researchers.

Howard held multiple academic posts in England, Canada and the United States, and this assisted in disseminating his ideas. For instance, Howard later spent time at the Department of Systems Design Engineering at the University of Waterloo. This supported the further development of metagame analysis into a problem structuring technique that then became known as conflict analysis. Metagame analysis and conflict analysis are distinguished by a strong orientation towards engineering problem solving, and therefore a desire to better model the extended moves or options required for conflict resolution or extensive engineering projects.

Fraser and Hipel (1984) argue that strategic mistakes happen when participants fail to understand their own values and payoffs. Mediation is, therefore, possible through a discussion of options and moves. The graph theoretic model of conflict resolution enhanced the earlier work of conflict theory by providing rigorous computational support for facilitation activities (Fang et al. 1993). This line of research is still vivid and ongoing, with a continued contribution of University of Waterloo scholars to the field (Hipel et al. 2014).

Another major contribution to the problem structuring field is the hypergame (Bennett 1977). Hypergames acknowledge that participants may perceive very different strategic situations, resulting in unnecessary conflict as well as unwanted social dilemmas. Players involved in a strategic game may have different ideas about the structure and nature of the game, and often do not have the full information about the other players' intentions and capabilities. Bennett was clearly inspired both by the emerging developments in the problem structuring domain, as well as the analysis of options work as advanced by Howard. Drama theory, as developed by Bryant (1998), is an acknowledged successor to the older tradition of hypergames (Mingers and Rosenhead 2004, p. 534). Drama theory maintained the theoretical foundations of hypergames, but enhanced the application of these ideas by relating them to story-telling and drama structures (Howard et al. 1992). The contribution of hypergames to problem structuring methods is acknowledged by their inclusion in a full chapter in a pioneering volume on problem structuring methods (Rosenhead and Mingers 2001).

A major outgrowth of game structuring methods occurred with exchange modelling (Coleman 1972; Stokman et al. 1985). These techniques, inspired by 
Table 1 Game structuring methods

\begin{tabular}{lcc}
\hline Name & Exemplary sources & Explanation \\
\hline Analysis of options & $\begin{array}{c}\text { Ackoff et al. (1969), } \\
\text { Howard (1971) }\end{array}$ & $\begin{array}{c}\text { Seeks a practical embodiment of games in real-life } \\
\text { settings }\end{array}$ \\
$\begin{array}{c}\text { Conflict analysis and } \\
\text { metagame analysis }\end{array}$ & $\begin{array}{c}\text { Fraser and Hipel } \\
(1984), \text { Howard } \\
\text { (1971) }\end{array}$ & $\begin{array}{c}\text { Uses a graphical representation of moves to better } \\
\text { understand the outcomes reached by players }\end{array}$ \\
$\begin{array}{c}\text { Graph model for } \\
\text { conflict resolution }\end{array}$ & $\begin{array}{c}\text { Fang et al. (1993) } \\
\text { Exchange modelling }\end{array}$ & $\begin{array}{c}\text { Provides computer implementation and support to } \\
\text { conflict analysis }\end{array}$ \\
Stokman et al., & $\begin{array}{c}\text { Uses an exchange among actors to better understand } \\
\text { collective decision processes }\end{array}$ \\
Hypergames & Bennett (1977) & $\begin{array}{c}\text { Evaluates information among players including } \\
\text { incomplete and imperfect sources }\end{array}$ \\
Drama theory & Howard et al. (1992), & $\begin{array}{c}\text { Translates game theoretic ideas in a practical way } \\
\text { using dramatic concepts and narratives }\end{array}$ \\
Theory of moves & Brams (1994) & $\begin{array}{c}\text { Expands existing games with a simple techniques to } \\
\text { expand opportunities }\end{array}$ \\
\hline
\end{tabular}

game theory, attempt to model group decision making. Both models involve the exchange of critical resources leading to mutually satisfactory outcomes. The origins of these techniques in game theory are discussed in Weintraub (1992).

A final development of note is the theory of moves (Brams 1994). The theory of moves argues that the rules of the game themselves are a source of conflict, leading to suboptimal outcomes for all who participate. Mediation is possible when participants expand the game by creating entirely new moves or options previously not present.

The principal techniques discussed are listed, and their varied refinements are summarized in Table 1. Two minor additions, not shown on the table, could also be considered here. Richards and Graham (1977) worked at the Wharton Business School, and inherited a tradition of work from the Social Systems Sciences program which was under development there. Also worthy of note are hypermaps, a minor offshoot of the hypergame and metagame tradition.

\subsection{Origination in game theory}

These five game structuring techniques, and their minor variations, originated in game theory. Figure 1 roots these five techniques in the foundational literature of game theory. Any such review begins with the work by von Neumann and Morgenstern (1944) as well as Nash's subsequent extensions (Nash 1950). The theory of social dilemmas prompted major work into the mediation of conflict (Flood and Dresher 1950). Luce and Raiffa (1957) provided an early and accessible text which addressed the nature of utility, the quality of decision making made under strategic constraint, and further considered the capability for effective mediation of games.

Another theoretical author of concern, Rapoport is significant in conflict studies (Rapoport 1970) and well aware of efforts to apply game theory in a live setting. 


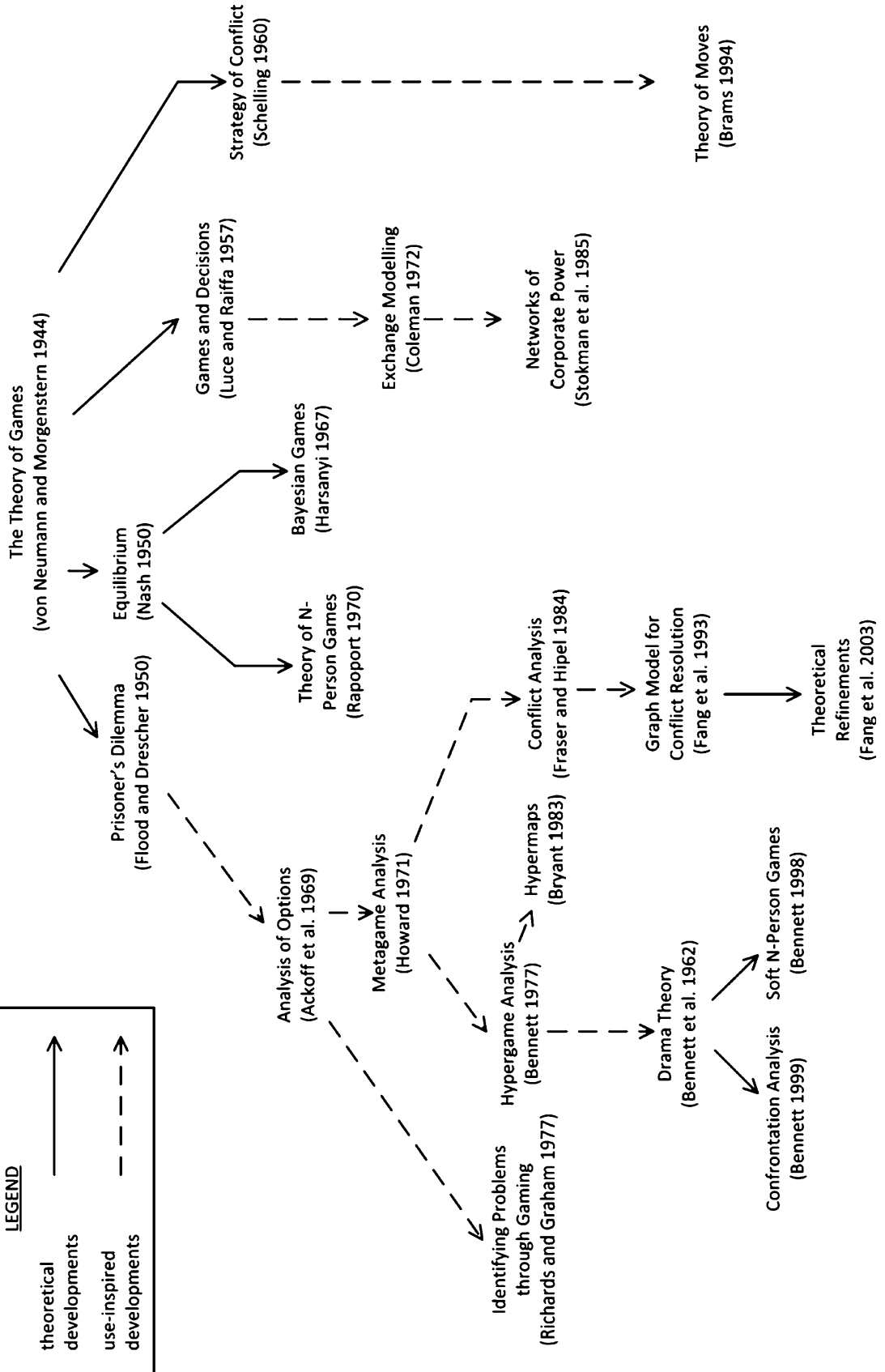

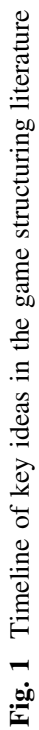


Schelling's work in conflict analysis, although deeply theoretical, also prompted practical efforts to modify games in a live setting (Schelling 1960). A final citation of note is the work of Harsanyi (1967), which established the modern theory of information economics, and set aside many concerns about the meaning and modelling of belief and information. These insights can be recognized in the more or less parallel development of hypergame analysis, on the role of information asymmetries in strategic games.

Also considered in this review are the more theoretical works which are part of the tradition. For instance, Howard (1987) describes metagames as a general theory of games for which analysis of options is its more practical implementation. Likewise, he describes confrontation analysis (Howard 1999) as a theoretical underpinning for the more practically minded work of drama theory. Howard also advanced a theory of "soft" n-person games (Howard 1998). The graph model for conflict resolution has also generated additional refinements, as for instance in (Fang et al. 2003a, b). In the final section of the paper, we reflect on progress in game theory, and game structuring methods, to provide recommendations for practice.

This review shows in part that there are considerable commonalities between the five game structuring methods, because they originate in part from similar game theory foundations. The review also shows the coevolution of theoretical and practical work. The theoretical work addresses matters such as the nature of strategic information, the nature of societal dilemmas, and the potential for cooperation. In the following subsection, we examine the practical and critical reception of the game structuring methods. This can be understood only in light of the parallel developments occurring in the pure game theory literature.

\subsection{Practical and critical reception to game structuring methods}

Game structuring techniques have inspired a rich body of applied work which spans over a quarter of a century. The work varies widely by domain, but includes international affairs (Avenhaus and Zartman 2007), industrial organization (Ghemawat 1997), public policy (Scharpf 1997), conflict studies (Ackoff 1969), and water resource applications (Fraser and Hipel 1980). Nonetheless, and despite the methodological generality of the technique, no study to our knowledge has described or analysed the specific methodological implications of working directly with stakeholders. A sample of the more influential studies reviewed on this point includes Bennett and Dando 1979, Giesen and Bennett 1979, Richelson 1979, Fraser and Hipel 1980, Shupe et al. 1980, Bennett et al. 1981, Said and Hartley 1982, Hipel et al. 1988, Li et al. 2004, Inohara et al. 2005 and Ma et al. 2005.

The particular theoretical contributions of Howard have perhaps been less lasting than the practical ones. Amongst other things, these theoretical works communicate an abiding concern with the various properties of equilibrium and of information in games. These abstract questions have distracted an applied community of researchers with questions which are primarily mathematical in nature, and not concerned with finding, identifying and mediating games in the real world. See for instance Rapoport (1974) and Greenberg et al. (2009) for further critical retrospection on Howard's contributions. 
Indeed, the existing game structuring literature provides limited or no interaction design. Despite the best intentions of previous authors, the literature on these techniques offers little guidance for participatory application in a live setting. Previous work largely presents game structuring methods as formal modelling techniques. As a result, more attention is paid to the internal consistency and formal logic than the actual engagement strategy. There are few exceptions. Howard (1987) shows attention to the details of the actual engagement. The role of the analyst as a mediator is also very clear in the work of the Waterloo school (Fang et al. 2003a, b; Wang et al. 2003).

What all these game structuring methods, and their varied refinements, share is a conviction that many real-world problems occur in an environment rife with strategic complexity. As Howard (1987, p. 6) writes:

the analysis can be the basis for a really interesting investigation of how the required interdependence between actors' intentions may come about. This, in reality, is through messy, changeful, emotional, deceitful, distrustful interactions between the actors, in which rational arguments, threats, promises and bluffs are exchanged, emotional stands and positions are taken up, reassessments are made, and so on.

The methods model difference of opinions, but also differences in the capabilities and actions of players. In short, the problems modelled by game structuring techniques involve modelling socially required interdependences between actors.

At this point, we have established the existence of a number of problem structuring methods which are almost exclusively focussed on a decision-making context. Progress in the field has been enduring, if rather slow. Despite early promise, these applied techniques have-with little exception-not been performed in a participatory manner in direct interaction with stakeholders. In the next section, we identify and isolate these elements of these models to discover the commonalities between the techniques. These techniques have developed in comparative isolation from one another, and a comparative analysis is needed.

\section{A common conceptual framework}

The goal of this section is to develop a basic conceptual framework for game structuring methods and models. As Fig. 1 illustrates, the roots of game structuring methods can be traced back to the Theory of Games. The game theoretic basis for analysis of options, and its offshoots, offers a high potential for generality. However, with a branching out of various techniques, the terminology has diversified. For a basic conceptual framework, more clarity on terminology and concepts is needed, including a choice for a unified terminology.

The fundamental elements of applied game theory are the players, actions, payoffs and the information of a game (Rasmussen 2005). The game structuring methods described above also enrich these elements with the outcome of the game, the result of the collective strategic choices of all the players. These strategic choices, the sequence of actions that players decide to take, are called moves. 
Outcomes are logically implied by moves and players, but it is nonetheless helpful to call this out explicitly, making these additional concepts within the various game structuring techniques.

Table 2 unites a variety of game structuring techniques by relating their various concerns to a common conceptual framework which is inherited from game theory. As noted in Table 2, these concerns are both theoretical as well as pragmatic. Theoretical concerns entail strategic hypotheses-how do these elements affect the play of the game? Pragmatic concerns entail the issues of modelling and representation-how will we distil elements found in the real world into a model for further analysis? Pragmatic concerns require that these game elements may be accessed by actors in the case, regardless of their prior knowledge of game theory.

Theoretically, some of these elements have been more problematic than others. The analysis of options method treats moves-outside of some pragmatic concerns about their operationalization — as being clear and readily accessible to participants. In contrast, it is the outcomes in the analysis of options which are perceived as being most problematic, and therefore in need of mediation through expert consultation. Complex real-world problems involve the assessment of multi-attribute choices and trade-offs. Despite this, the analysis of options method argues for simple rank scaling of outcomes, performed by analysts on behalf of actors. In short, the techniques argue that payoffs are readily accessible, although not capable of being measured with precision (Howard 1971).

Inspired by game theory, the reviewed methods offer a comprehensive perspective on strategic behaviour. They are, however, purposefully abridged in describing the physical or natural system where strategies occur, and are therefore not a replacement for the larger family of problem structuring methods. Concluding, in this section, we provided a common conceptual framework for understanding game structuring elements. In the next section, we review available methodologies for investigating these game elements in a live setting with key actors.

\section{Towards a participatory game structuring approach}

Using these elements, we now discuss our own general interaction design in this section. The field of public participation and modelling constitutes a broad and rapidly growing field of research. The literature varies from theoretical appraisals of the state-of-the-art (Rowe and Frewer 2000) to inventories of available methods and recommendations for conduct in specific domains (Chambers 1994). Other sources in the literature adapt specific modelling techniques such as multi-criteria decision analysis (Ansell and Gash 2008) or system dynamics (Vennix 1996) to better fit the needs of participatory modelling. A much smaller subset of literature offers a generic framework for participatory and interaction design.

In this spirit, we work with a general purpose framework for participatory modelling offered by Voinov and Bousquet (2010). This general framework offers a structure to incorporate other methodological elements particularly suited to problem structuring methods. We incorporate the general analysis of options conversation as advocated by Howard (1987), with elements of creativity, group 


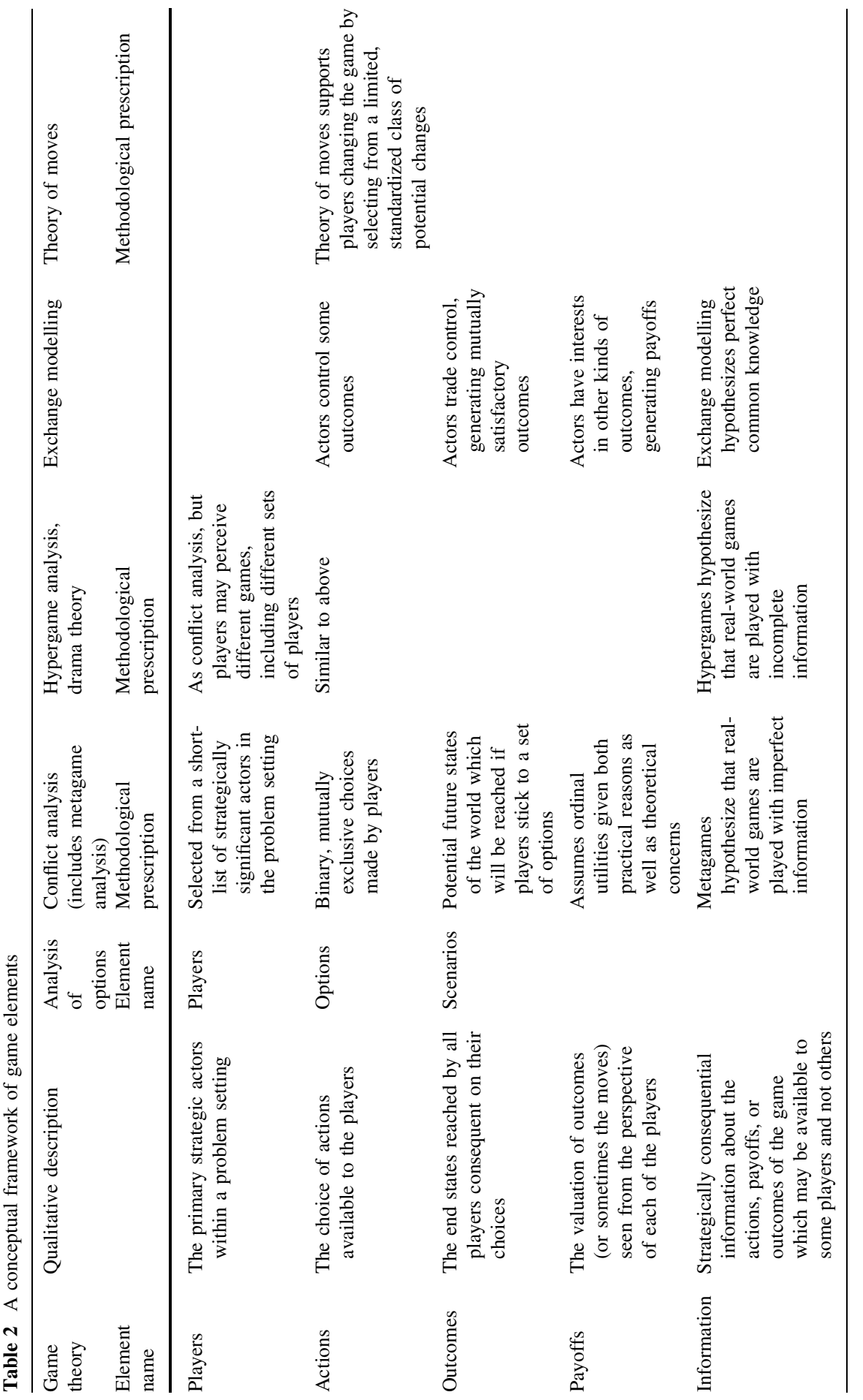


decision making and planning (Franco and Montibeller 2010). This is consistent with current practices in other problem structuring methods.

\subsection{Participatory modelling within game structuring techniques}

The use of workshop settings for problem structuring is considered explicitly within the problem structuring literature. Franco and Montibeller (2010) argue for three basic tasks. In each of these tasks, the facilitator plays a crucial role. The tasks are "divergent thinking," "the groan zone," and "convergent thinking." These mirror a more generic structure for brainstorming and creativity. The literature on group decision-making processes also contributes useful elements for a workshop setting. Roper et al. (2012) describe three elements which they claim unify all structured group decision processes - the processes of talk, feedback, and estimation. Additionally, assumption-based planning offers helpful advice for managing uncertainty in groups, and it includes extended recommendations for organizational engagement as well as direct consultation with a decision maker (Dewar et al. 1993).

A literature on participatory modelling includes Voinov and Bousquet (2010), who provide guidelines and best practices for any such effort. The authors review a number of related frameworks for engaging with stakeholders, and a number of different analytical techniques which may be used with stakeholders. Most significantly, the authors ask which kind of participation is needed. Drawing upon Pretty (1995), the authors describe five different sorts of participation:

- Passive participation, in which the objective is just to inform people;

- Extracting information from people for the scientist who needs data;

- Participation to support the decisions, in which stakeholders are used to promote and articulate the chosen decisions;

- Interactive participation, where stakeholders share the diagnostic and analytical methods and tools or results;

- Self-organization, where the lessons from the participatory process are transformed into decisions by the stakeholders themselves (Voinov and Bousquet 2010: 1272)

The most far-reaching type of participation, and the type most relevant for problem structuring engagements is self-organization "where the lessons from the participatory process are transformed into decisions by the stakeholders themselves." Voinov and Bousquet (2010) also describe a generic modelling process suitable for any number of different analytical techniques, which we will use as a basis for our general design, described more fully below.

\subsection{A general design for game structuring methods}

Game structuring methods may be updated and integrated with other participatory modelling methods by incorporating its concerns within a six-step process 
(Table 3). The first step involves identifying the players. This step, already noted in the analysis of options method, is expanded to consider the full decision-making context of the problem, including the decision makers and affected stakeholders. This process is known as describing the arena of the problem (Hermans and Cunningham 2013). Stakeholder analysis and identification techniques such as those described by Bryson (2004) may be usefully employed to support this step.

Project goals need to be set. There are at least three distinct goals for the exercise which may be set with participants. One goal is to enable learning and interaction among the participants. Active participation in the modelling process, with a summary report for all involved, may be entirely sufficient to enable this goal. Elements of serious gaming or role playing may be usefully introduced here as we move from decision consultation to a fully participatory process. While this goal enables commitment, it may also be useful to establish potential action. If this is the goal of the exercise, then more scientific or technical elements may need to be introduced, such as setting functional requirements for further design work. A third goal of the exercise may be to anticipate potential strategic behaviour on the part of other actors in the system, and to develop useful counter-strategies.

Step two involves analysing the system context. This entails a substantive process of systems modelling. We abridge our discussion of this step-not because the process is insignificant-but rather because it is well covered by other methodologies, including the aforementioned subset of problem structuring methods that focus more on the system environment (c. f. Eden and Ackermann 1998). See for instance (Wang et al. 2003) for a thorough systems analysis as a precursor to a full game analysis of a (water) policy setting. It is also necessary during this step to assess strategic vulnerabilities-whether from external events, deliberate actions taken by other players or current assumptions in relation to the understanding of the system and its workings.

Step three involves the development of potential game outcomes. Unlike Howard (1987), but in keeping with Dewar et al. (1993), we first consider the outcomes of the game before fully entertaining a range of possible actions. In this step, we advocate deliberately selecting the widest possible array of outcomes for discussion. This early development of possible outcomes is a conscious choice, to open the space for future discussion and negotiation (see step five below). One of the created outcomes should be dedicated to the status quo, or how things may progress if no action is taken to deviate from existing paths. The status quo is an important benchmark for setting future goals and expectations (Li et al. 2004). Here, we are using the meaning of outcomes as possible strategic futures as described as scenarios by Howard (1987) (see Table 2). Howard's focus on strategic futures rather than futures created by external events or contexts is unusual, but not without precedent in the literature. See for instance Rhyne (1981). The distinction between external random events and external strategic actions by opposing players is not always clearly delineated in the literature. For instance, a widely cited framework for public policy conflates a wide range of variables under the label "external forces" (Walker 2000).

In conventional game structuring approaches, this step of developing actions comes earlier in the analysis process, where it precedes the establishment of 


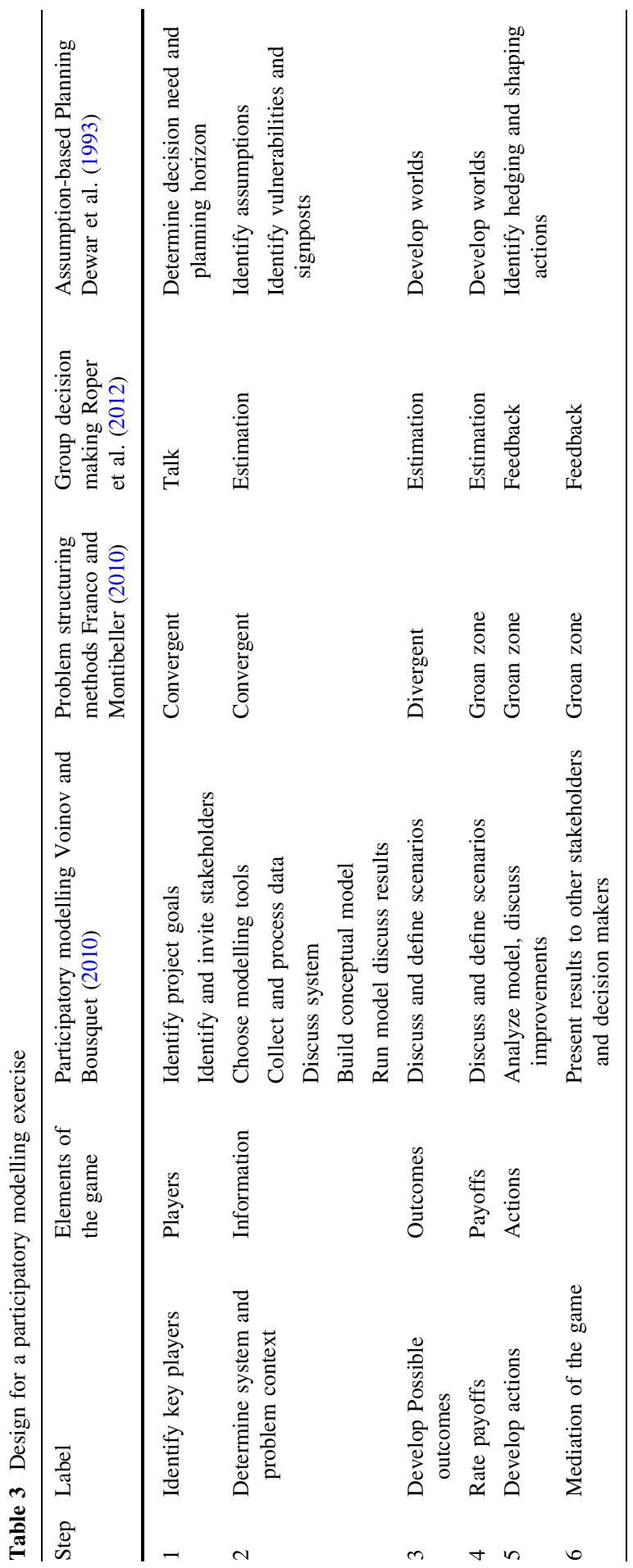


possible outcomes. In an interactive and joint application, following the conventional sequence could make an open debate uncomfortable or impossible, and could lead to positional bargaining rather than interest-based negotiations (Fisher et al. 1991; Thompson 2011). Discussing possible outcomes, positioned in a somewhat distant future is likely to offer a more fruitful basis for further discussion. It enables a more natural focus on the underlying interests, rather than on the immediate actions and positions of the various players.

Step four involves the analysis of payoffs for the various actors. Payoffs are stakeholder-specific valuations of outcomes of interest, which are ultimately derived from the particular system under study. An understanding of system functioning derived from step 2 is, therefore, necessary here. In many systems, it is permissible to entertain mixtures of outcomes. Enacting this step entails the assessment of the ordinal utilities of each of the potential outcomes developed in step four. This is performed on behalf of each of the key players of the game, possibly using role playing and/or surrogates whereby payoffs may be estimated by other informed participants. A simple rank ordering of the $n$ outcomes from least preferred (rank one) to most preferred (rank $n$ ) is sufficient here. More elaborate treatment of the valuation of outcomes is possible, if respondents display a lot of inter-group and between-group reliability in assessing the preferences. It may be appropriate at this stage to develop objective hierarchies for each of the players. Then, descriptive labels corresponding to particular objectives may be assigned to each of the potential outcomes. This can generate a wealth of discussion regarding valued outcomes for each of the players.

Step five involves using a planning approach model to develop possible actions. A planning approach involves thinking first of outcomes and only later of actions. Accordingly, this step requires evaluation of all the outcomes from step five to determine a range of possible actions for each of the players. The participants should strive here to identify which sets of actions would be necessary to create each of the potential futures. Participatory methods for framing policies in pursuit of desirable future outcomes are the main focus of backcasting efforts-see for instance (Quist and Vergagt 2006). It is important at this stage that the participants remain agnostic about whether a player would or would not take a particular action; all should be listed. Entirely new actions may be proposed during this stake to hedge losses, or to shape and promote positive outcomes for a particular player. This completes identifying the major elements of the game.

Step six entails offering further mediation. Social dilemmas involve players being trapped in suboptimal outcomes because of a lack of communication, cooperation, or external mediation. Analysts can help by describing the space of possible win-win outcomes, thus adding further support to get players into a process called integrative negotiation (Thompson 2011).

Identifying the space of win-win outcomes requires the sequential elimination of dominated outcomes-outcomes which make one player worse off without demonstrably improving the payoffs for another. This may require exploring combinations of outcomes. The remaining outcomes which have not been eliminated will be Pareto optimal. These outcomes can form a basis for further discussion whether the analyst seeks the common good, or is strategizing on the sole 
behalf of one of the players. An example of this process is demonstrated in a second paper (Slinger et al. 2014).

Further distributive negotiations (Thompson 2011), where players discuss the relative division of rewards from cooperation, may then occur. Various other game structuring techniques make further analytical assumptions about rationality and game equilibria and may be employed as warranted (Howard 1971; Fraser and Hipel 1984). In this stage, it is important to keep the differences between the win-win outcomes and the non-cooperative outcomes in mind, to prevent a digression away from an integrative bargaining mode.

In practice, a mix of mediation approaches may be the most useful, constructive choice. Process and stakeholder management recommendations may be one useful output of the exercise (de Bruijn et al. 2010). Considerations of principled negotiation or arbitration may be another useful output for participants seeking more constructive interactions with others (Fisher et al. 1991). Or the participants may be seeking ways to change the play of the game, as for instance discussed by Brams (1994) or by Schelling (1960). These mediation techniques provide results intermediate between the project goals of building commitment, developing action, and strategizing with other stakeholders.

Throughout the process, but especially from step five onwards, when actions to realize outcomes are being identified, additional players, not previously conceived as critical, may be identified. If the game structuring process is done in a single workshop or meeting, the process may simply be continued and completed, but afterwards an evaluation is needed of the implications of the absence and role of the additional players. An alternative could be to continue the workshop with another event, with the more complete set of players being represented.

\section{Conclusions}

Problem structuring methods are uniquely suitable for analysing complex problems. A subset of the literature argues that it is appropriate to select problem structuring methods given specific sources of this complexity. If the specific source of the problem is strategic in character, it may be appropriate to deploy specialized problem structuring methods developed to clarify strategic decision making. Here, strategic takes on a rather specific meaning-strategy involves actors who are knowingly engaged in making consequential decisions which affect both themselves as well as others. Complexity emerges from the intersection of these decisions.

A more commonplace definition of strategic involves decisions made at a larger scale, for the longer term. There is an implicit contrast with tactical or operational decision making, which is seen as shorter term, and with a smaller system scale or scope. This second sense of strategic requires no specific source of actor complexity. Perhaps, both the system and the actor context may be complex, or perhaps the interaction between systems and actors is itself the source of the problem complexity. In this sense, the complexity may be integral, and cannot easily be broken down into its contextual elements. 
Nonetheless, the practicalities of working with actors in a participatory and problem structuring setting may require facilitators who encourage participants to focus their attention to specific elements of the problem. A goal of problem structuring methods is, therefore, to produce inventories of problem elements which are ecologically and contextually valid across a broad range of problem settings. For this reason, and others, this article focussed on a set of methods loosely inspired by game theory. These methods offer an inventory of elements common across strategically complex problems.

These game theory inspired methods include, but are not limited to, analysis of options, conflict analysis, exchange modelling, hypergame analysis and the theory of moves. In this paper, we characterize these methods as a family of "game structuring methods." These techniques are an integral and historical part of the problem structuring method.

Despite the significance of these techniques, the theory and rationale behind these techniques have become obscured. A family tree of methods (presented earlier as Fig. 1) shows that these techniques have a common lineage in game theory. The variety of names by which common game structuring elements are known (presented earlier in Table 2) demonstrates the gradual divergence occurring across these varied techniques. The game structuring literature has tended to engage in theoretical concerns rather than the real-world challenges of finding games within a decision-making context. Methodological innovation for its own sake has partially obscured a set of common strategic foundations shared across game structuring techniques. A contribution of this paper, therefore, has been to trace the theoretical pre-commitments of this branch of problem structuring methods, and perhaps encourage new contributions and offshoots within this tradition.

Practice-oriented recommendations are, therefore, to not make the same mistakes: complement the existing research with a greater variety of methods for finding games, and develop and test a greater variety of designs for conducting game structuring workshops with stakeholders. Furthermore, practitioners should seek inspiration for their games from real-world settings rather than theoretical preconceptions. Practitioners should adapt existing game structuring methods when the assumptions and components match the needs of their cases. When no existing methods exist, practitioners should assemble their own game structuring methods from a ready supply of components as discussed in this paper. And, when new theoretical issues emerge, these issues should be translated into the formal, standardized components of the game theory community rather than adopt and proliferate diverse names and structures.

One might critique the selection of techniques discussed in this paper as being idiosyncratic, or haphazard. We have endeavoured to demonstrate, however, that this selection of techniques is the result of direct, vertical transmission of ideas from a small number of influential pioneers in the field. Given the greying of the literature, these contributions are in danger of being forgotten. Further, it is a good time to take stock of what is successful or useful in these game structuring methods so that these elements may be reincorporated into future work.

It is clear that, in retrospect, this subset of methods has not fully delivered on their promise of contributing to direct participation with key actors and 
stakeholders. This lack of delivery is caused in part by an incomplete framework for analysis. The game theory elements which inspired the game structuring methods provide useful formalism and rigour, but they can never replace an explicit engagement strategy. To this end, we review a subset of the literature on participatory modelling, and attempt a synthesis between game structuring literatures and participatory modelling.

A contribution of this paper is, therefore, to unify the older literature with newer research involving participatory modelling methods. In this paper, we suggest a flexible engagement strategy with specific steps for building models in tandem with actors. These steps are neither obvious, nor directly implied by the formal analysis procedures. We lead the discussion with stakeholders using outcomes rather than actions. Actions are a problematic basis with which to design stakeholder engagements. Capabilities analysis and the corresponding policy or strategy design are often the culminating products of an analysis rather than the first steps. Paradoxically, leading a discussion with a set of potential actions can hinder further commitment to action among actors and stakeholders.

In contrast, leading the discussion with potential actor and system outcomes builds engagement, and enables further constructive discussion among stakeholders. Hence, we observe many of the constructive benefits of working with outcomes that are seen in scenario analyses. Outcomes also permit the further incorporation of role-playing elements as part of the process. In particular, an outcomes analysis enables participants to change their frame of reference and to more fully understand the perspectives of other strategic actors in the setting. Outcomes may, therefore, be a hook by which additional participatory or group engagement activities may be incorporated. The emotive and imaginative character of this activity has been previously highlighted, albeit more as an art, rather than a concrete activity for engagement (Howard et al. 1992).

An additional methodological benefit of the proposed methodology is a clear separation between structure, analysis, and the mediation of the problem. Previous work has linked structure and analysis in a manner which may often be counterproductive. Instead, the specifics of the case should detail when and if more elaborate analyses are needed. Similarly, there are a variety of different possible mediation strategies. A contribution of this work is to discuss some foundational techniques for mediating conflict. These involve identifying and sharing with players the range of inferior, but stable outcomes, and discussing the Pareto frontier of possibilities. Describing the current status quo is also advocated, as it circumscribes the set of negotiated outcomes which might be achieved in the future.

Of course, many of the caveats and difficulties of problem structuring methods and participatory modelling of a more general character still remain. Despite this, the innovations described and developed in this paper are useful for advancing the sub-field of game structuring methods. The need for participatory use of game structuring techniques may be greater, and the facilitation challenges even higher, than system structuring efforts. Working with system structuring and game structuring techniques in tandem will help to develop a commitment for action. This commitment will not only be based on an understanding of actions taken on the 
system of interest, but also based on an understanding of what role the various actors have in implementing these actions.

Acknowledgments The authors would like to thank the comments of four anonymous reviewers which greatly improved the paper. Furthermore, the authors gratefully acknowledge financial support from the Next Generation Infrastructures (NGI) Foundation and the South Africa Netherlands research Programme on Alternatives in Development (SANPAD).

\section{References}

Ackermann F (2012) Problem structuring methods 'in the dock': arguing the case for soft O.R. Eur J Oper Res 219(3):652-658

Ackermann F, Franco A, Gallupe B, Parent M (2005) GSS for Multi-organizational collaboration: reflections on process and content. Group Decis Negot 14(4):307-331

Ackoff RL, Davis P, Delesie L, Ducamp A, Emshoff JR, Hall J, Howard N, Mennis B, Monroy G, Smith JG (1969) Conflicts and their escalation: metagame analysis, Trustees of University of Pennsylvania, vol I

Ansell C, Gash A (2008) Collaborative governance in theory in practice. J Public Adm Res Theor 18(4):543-571

Avenhaus R, Zartman IW (eds) (2007) Diplomacy games: formal models and international negotiations. Springer, Heidelberg

Bennett PG (1977) Toward a theory of hypergames. Omega 5:749-751

Bennett PG, Dando MR (1979) Complex strategic analysis: hypergame study of the fall of France. J Oper Res Soc 30(1):23-32

Bennett PG, Huxham CS, Dando MR (1981) Shipping in crisis: a trial run for live application of the hypergame approach. Omega 9(6):579-594

Brams SJ (1994) Theory of moves. Cambridge University Press, Cambridge

Bryant JW (1998) Analyzing collaboration as drama. Syst Pract Action Res 11(4):403-417

Bryson J (2004) What to do when stakeholder matters. Stakeholder analysis and identification techniques. Public Manag Rev 6(1):21-53

Chambers R (1994) The origins and practice of participatory rural appraisal. World Dev 22(7):953-969

Checkland P, Winter MC (2006) Process and content: two ways of using SSM. J Oper Res Soc 57(12): 1435-1441

Coleman JS (1972) Systems of social exchange. J Math Sociol 2:145-163

Cushman M (2006) Book review. Visible thinking: unlocking causal mapping for practical business results. J Oper Res Soc 57(7):880-882

de Bruijn H,ten Heuvelhof E, in't Veld RJ (2010) Process management: why project management fails in complex decision making processes, 2nd edn. Springer, Berlin

DeTombe DJ (2002) Complex societal problems in operational research. Eur J Oper Res 140:232-240

Dewar JA, Builder CH, Hix WM, Levin M (1993) Assumption-based planning: a planning tool for very uncertain times, RAND Corporation

Eden C, Ackermann F (1998) Making strategy: the journal of strategic management. Sage Publications, New York

Eden C, Ackermann F (2004) Cognitive mapping expert views for policy analysis in the public sector. Eur J Oper Res 152(3):615-630

Fang L, Hipel KW, Kilgour DM (1993) Interactive decision making: the graph model for conflict resolution. Wiley, New York

Fang LP, Hipel KW, Kilgour DM, Peng XYJ (2003a) A decision support system for interactive decision making, part I: model formulation. IEEE Trans Syst Man Cybern Part C Appl Rev 33(1):42-55

Fang LP, Hipel KW, Kilgour DM, Peng XYJ (2003b) A decision support system for interactive decision making, part II: analysis and output interpretation. IEEE Trans Syst Man Cybern Part C Appl Rev 33(1):56-66

Fisher R, Ury WL, Patton B (1991) Getting to yes, vol 2. Penguin Books, New York

Flood M, Dresher M (1950) Social dilemmas. RAND Corporation, Santa Monica, California

Franco LA, Montibeller G (2010) Facilitated modelling in operational research. Eur J Oper Res 205:489-500 
Fraser NM, Hipel KW (1980) Metagame analysis of the poplar river conflict. J Oper Res Soc 31(5):377-385

Fraser NM, Hipel KW (1984) Conflict analysis: models and resolutions. North-Holland, New York

Ghemawat P (1997) Games businesses play: cases and models. MIT Press, Cambridge

Giesen MO, Bennett PG (1979) Aristotle fallacy: hypergame in the oil shipping business. Omega 7(4):309-320

Greenberg J, Gupta S, Luo X, Luo X (2009) Mutually acceptable courses of action. Econ Theor 40(1):91-112

Harsanyi J (1967) Games with incomplete information played by "Bayesian" players, part I: the basic model. Manag Sci 14(3):159-182

Hermans LM, Cunningham SW (2013) Actor models for policy analysis. Public policy analysis-new developments. In: Thissen WAH, Walker WE. Springer, New York, pp 185-213

Hipel KW, Wang MH, Fraser NM (1988) Hypergame analysis of the Falkland Malvinas conflict. Int Stud Quart 32(3):335-358

Hipel KW, Kilgour DM, Kinsara RA (2014) Strategic investigations of water conflicts in the middle east. Group Decis Negot 23(3):355-376

Howard N (1971) Paradoxes of rationality: games, metagames, and political behavior. The MIT Press, Cambridge

Howard N (1987) The present and future of metagame analysis. Eur J Oper Res 32:1-25

Howard N (1998) N-person 'Soft' games. J Oper Res Soc 49:144-150

Howard N (1999) Confrontation Analysis: How to Win Operations Other than War. CCRP, Washington, D.C

Howard N, Bennett PG, Bryant JW, Bradley M (1992) Manifesto for a theory of drama and irrational choice. J Oper Res Soc 44:99-103

Inohara T, Hipel KW, Walker S (2005) Conflict analysis approaches for investigating attitudes and misperceptions in the War of 1812. J Syst Sci Syst Eng 16(2):181-200

Jackson MC, Keys P (1984) Towards a system of systems methodologies. J Oper Res Soc 35(6):473-486

Li KW, Kilgour DM, Hipel KW (2004) Status quo analysis of the Flathead River conflict. Water Resour Res 40(5)

Luce RD, Raiffa H (1957) Games and decisions: introduction and critical survey. Dover Publications, Mineola

Ma J, Hipel KW, De M (2005) Strategic analysis of the James Bay hydroelectric dispute in Canada. Can J Civ Eng 32(5):868-880

Mingers J (2003) A classification of the philosophical assumptions of management science methods. J Oper Res Soc 54(6):559-570

Mingers J, Rosenhead J (2004) Problem structuring methods in action. Eur J Oper Res 152:530-554

Nash J (1950) Equilibrium points in n-person games. Proc Natl Acad Sci 36(1):48-49

Pretty JN (1995) Participatory learning for sustainable agriculture. World Dev 23(8):1247-1263

Quist J, Vergagt P (2006) Past and future of backcasting: the shift to stakeholder participation and a proposal for a methodological framework. Futures 38:1027-1045

Rapoport A (1970) The theory of N-person games: concepts and applications. Michigan, University of Michigan Press, Ann Arbor

Rapoport A (1974) Review. Paradoxes of rationality: theory of metagames and political behavior. Public Choice 19:139-143

Rasmussen E (2005) Games and information: an introduction to game theory. Wiley-Blackwell, Hoboken

Rhyne R (1981) Whole-pattern futures projection using field anomaly relaxation. Technol Forecast Soc Chang 19:331-360

Richards LD, Graham RJ (1977) Identifying problems through gaming. Interfaces 7(3):76-79

Richelson JT (1979) Soviet strategic doctrine and limited nuclear operations: metagame analysis. J Confl Resolut 23(2):326-336

Rittel HWJ, Webber MM (1973) Dilemmas in a general theory of planning. Policy Sci 4:155-169

Roper AT, Cunningham SW, Porter AL, Mason TW, Rossini FA, Banks J (2012) Forecasting and management of technology, 2nd edn. Wiley, Hoboken

Rosenhead J, Mingers J (eds) (1989) Rational analysis for a problematic world. Wiley, Chichester

Rosenhead J, Mingers J (eds) (2001) Rational analysis for a problematic world revisited. Wiley, Chichester

Rowe G, Frewer LJ (2000) Public participation methods: a framework for evaluation. Sci Technol Human Values 25(3):3-29 
Said AK, Hartley DA (1982) A hypergame approach to crisis decision-making: the 1973 middle east war. J Oper Res Soc 33(10):937-948

Scharpf FW (1997) Games real actors play: actor-centered institutionalism in policy research. Westview Press, Boulder

Schelling T (1960) The strategy of conflict. Harvard University Press, Cambridge

Shupe MC, Wright WM, Hipel KW (1980) Nationalization of the Suez Canal: a hypergame analysis. J Conflict Resolut 24(3):477-493

Slinger JH, Cunningham SW, Hermans LM, Linnane SM, Palmer CG (2014). A game structuring approach with application to Estuary management in South Africa. J Decis Process (in press)

Stokman FN, Ziegler R, Scott J (eds) (1985) Networks of corporate power: a comparative analysis of ten countries. MA Polity Press, Cambridge

Thissen WAH, Walker WE (eds) (2013) Public Policy Analysis. Springer, Berlin

Thompson L (2011) The mind and heart of the negotiator. Pearson, Boston

Vennix JAM (1996) Group model building: facilitating team learning using system dynamics. Wiley, Hoboken

Voinov A, Bousquet F (2010) Modelling with stakeholders. Environ Model Softw 25:1268-1281

von Neumann J, Morgenstern O (1944) Theory of games and economic behavior. Princeton University Press, Princeton, New Jersey

Walker WE (2000) Policy analysis: a systematic approach to supporting policymaking in the public sector. J Multi Criteria Decis Anal 9(1-3):11-27

Wang LZ, Fang L, Hipel KW (2003) Water resources allocation: a cooperative game theoretic approach. J Environ Inform 2(2):11-22

Weintraub ER (ed) (1992) Toward a history of game theory. Duke University Press, Durham 